\title{
Differential gene expression of human chondrocytes cultured under short-term altered gravity conditions during parabolic flight maneuvers
}

Markus Wehland ${ }^{1 \dagger}$, Ganna Aleshcheva ${ }^{1 \dagger}$, Herbert Schulz ${ }^{2,3}$, Katrin Saar ${ }^{2}$, Norbert Hübner $^{2}$, Ruth Hemmersbach ${ }^{4}$, Markus Braun ${ }^{5}$, Xiao Ma ${ }^{6}$, Timo Frett ${ }^{7}$, Elisabeth Warnke', Stefan Riwaldt ${ }^{1}$, Jessica Pietsch ${ }^{1}$, Thomas Juhl Corydon ${ }^{6}$, Manfred Infanger ${ }^{1}$ and Daniela Grimm ${ }^{*}$

\begin{abstract}
Background: Chondrocytes are the main cellular component of articular cartilage. In healthy tissue, they are embedded in a strong but elastic extracelluar matrix providing resistance against mechanical forces and friction for the joints. Osteoarthritic cartilage, however, disrupted by heavy strain, has only very limited potential to heal. One future possibility to replace damaged cartilage might be the scaffold-free growth of chondrocytes in microgravity to form 3D aggregates.

Results: To prepare for this, we have conducted experiments during the 20th DLR parabolic flight campaign, where we fixed the cells after the first (1P) and the 31st parabola (31P). Furthermore, we subjected chondrocytes to isolated vibration and hypergravity conditions. Microarray and quantitative real time PCR analyses revealed that hypergravity regulated genes connected to cartilage integrity (BMP4, MMP3, MMP10, EDN1, WNT5A, BIRC3). Vibration was clearly detrimental to cartilage (upregulated inflammatory $I L 6$ and $I L 8$, downregulated growth factors EGF, VEGF, FGF17). The viability of the cells was not affected by the parabolic flight, but showed a significantly increased expression of anti-apoptotic genes after 31 parabolas. The IL-6 release of chondrocytes cultured under conditions of vibration was not changed, but hypergravity $(1.8 \mathrm{~g})$ induced a clear elevation of IL-6 protein in the supernatant compared with corresponding control samples.
\end{abstract}

Conclusion: Taken together, this study provided new insights into the growth behavior of chondrocytes under short-term microgravity.

Keywords: Chondrocytes, Gene expression, Microgravity, Hypergravity, Vibration, Cytokines

\section{Background}

Joint friction at the extremities of long bones is reduced by articular cartilage. This kind of tissue is highly specialized, avascular, not innervated and consists mainly of a single cell type: the chondrocytes. The chondrocytes are tightly embedded in an extracellular matrix (ECM), which is composed of a network of collagens

\footnotetext{
* Correspondence: dgg@biomed.au.dk

${ }^{\dagger}$ Equal contributors

${ }^{6}$ Department of Biomedicine, Aarhus University, Wilhelm Meyers Allé 4, DK-8000 Aarhus C, Denmark

Full list of author information is available at the end of the article
}

(predominantly collagen type II) and aggrecan. The collagen network contributes to the strength and mechanical resistance of cartilage tissue, whereas the aggrecan, a proteoglycan, comprising such molecules as chondroitin sulfate or keratin sulfate, is responsible for its viscoelasticity and flexibility due to its ability to absorb and retain considerable amounts of water [1-3]. Degenerative diseases of the cartilage like osteoarthritis are characterized by a progressive degradation of the ECM, caused by the increased secretion of matrix metalloproteinases (MMP) $[4,5]$. This process is triggered by pro-inflammatory cytokines, such as tumor necrosis factor- $\alpha$ (TNF- $\alpha)$ or interleukin- $1 \beta$

\section{Ciomed Central}

(c) 2015 Wehland et al.; licensee BioMed Central. This is an Open Access article distributed under the terms of the Creative Commons Attribution License (http://creativecommons.org/licenses/by/4.0), which permits unrestricted use, distribution, and reproduction in any medium, provided the original work is properly credited. The Creative Commons Public Domain Dedication waiver (http://creativecommons.org/publicdomain/zero/1.0/) applies to the data made available in this article unless otherwise stated. 
(IL-1 $\beta)$, which are transported into the cartilage via the synovial fluid $[6,7]$. The absence of vasculature and the extremely limited influx of chondrocyte progenitor cells [8] limit the tissues healing and restorative potential, so that in advanced stages of osteoarthritis a surgical replacement of the affected joint with a prosthesis is usually necessary.

Apart from the influences of age and use intensity, other factors have been found to mediate cartilage integrity. Most notably, microgravity $(\mu g)$ has a strong impact on cartilage. It has been reported, that astronauts, after staying a longer time in Space, suffer from a reduction of cartilage mass [9] due to mechanical unloading. In addition, when cultured in Space, cartilage tissue showed a reduced aggrecan density and a less-organized collagen subtype 2 organization hinting towards an impaired resistance to mechanical stress and breaking [10,11]. It is therefore of high interest, to study the impact of microgravity on chondrocytes. On the one hand, this will help to understand the detrimental effects of prolonged stays in Space on the cartilage, but on the other it might also help to find ways to counteract this phenomenon in Space as well as to ameliorate cartilage problems caused by wear on Earth in the future.

Microgravity $(\mu g)$ provides unique conditions for cell and tissue growth. It has been shown on various cell types, including chondrocytes, that cultivation under conditions of $\mu g$ can induce the formation of 3D aggregates. These aggregates are especially interesting, as they do not require any potentially interfering scaffolding like those being generated under normal gravity conditions [12-16].

Cell cultivation in Space, however, is an extremely complicated and expensive venture. Therefore, pre-studies such as a parabolic flight, providing $31 \times 22 \mathrm{~s}$ of short-term real $\mu g$, or simulated $\mu g$ on ground-based facilities such as the rotating wall vessel bioreactor, clinostats or the random positioning machine (RPM) have been established [17-19]. Especially the parabolic flight is an attractive method to achieve real $\mu g$ without going into Space. It should be taken into consideration, however, that every $\mu g$-phase is flanked by two $20 \mathrm{~s}$-lasting hypergravity phases of $1.8 \mathrm{~g}$. Moreover, during the flight vibrations occur and have to be taken into account for interpretation of the results [20].

This study aimed to investigate the influence of shortterm real $\mu g$ during a parabolic flight campaign on the gene expression profiles of cultivated chondrocytes. In addition, the effects of $1.8 \mathrm{~g}$ hypergravity as well as of vibration in an extent comparable to those during a parabolic flight were separately investigated.

\section{Results}

Influence of hypergravity on chondrocyte gene expression Using the Microarray analysis technique, we found a total of 210 genes (top 30 are listed in Table 1, for a complete list see Additional file 1) which were significantly differentially
Table 1 Top 30 most differentially expressed genes under hypergravity as detected by microarray analysis

\begin{tabular}{|c|c|c|}
\hline Symbol & p-value & Fold-Change $(1.8 g$ vs. $1 g)$ \\
\hline ANGPTL4 & $3,41336 \mathrm{E}-05$ & 4,82382 \\
\hline ADAM19 & $1,31184 \mathrm{E}-03$ & 3,65686 \\
\hline LOC401233 & $3,46212 \mathrm{E}-05$ & 3,59384 \\
\hline$A R H G D I B$ & $6,38141 \mathrm{E}-06$ & 3,37183 \\
\hline TAGLN & $4,66727 \mathrm{E}-04$ & 3,34324 \\
\hline CTAG2 & $4,76891 \mathrm{E}-05$ & 3,28068 \\
\hline PRG4 & $2,57465 \mathrm{E}-04$ & 3,27652 \\
\hline CXCL12 & $3,59100 \mathrm{E}-04$ & 3,20598 \\
\hline LAMC2 & $4,52723 \mathrm{E}-05$ & 3,09657 \\
\hline CXCL12 & $3,10216 \mathrm{E}-05$ & 3,09447 \\
\hline RAGE & 4,92007E-04 & 3,07122 \\
\hline PRG4 & $2,73879 \mathrm{E}-04$ & 3,01963 \\
\hline MSLN & $1,29948 \mathrm{E}-06$ & 2,95963 \\
\hline SRGN & $6,35801 \mathrm{E}-05$ & 2,93607 \\
\hline ZNF185 & $7,53193 \mathrm{E}-06$ & 2,92161 \\
\hline MTIF & $5,01022 \mathrm{E}-06$ & $-3,61603$ \\
\hline FGFBP2 & $1,36152 \mathrm{E}-04$ & $-3,68509$ \\
\hline COL2A1 & $1,85922 \mathrm{E}-04$ & $-3,70943$ \\
\hline HYAL1 & $1,90804 \mathrm{E}-05$ & $-3,83367$ \\
\hline MMP3 & $7,88772 \mathrm{E}-05$ & $-3,88035$ \\
\hline LRRC32 & $1,77468 \mathrm{E}-05$ & $-3,88223$ \\
\hline SMOC2 & $2,93763 \mathrm{E}-05$ & $-3,89646$ \\
\hline SERPINA3 & $4,50468 \mathrm{E}-06$ & $-4,56156$ \\
\hline STMN2 & $4,95960 \mathrm{E}-04$ & $-4,71568$ \\
\hline OGN & $2,69302 \mathrm{E}-05$ & $-4,95328$ \\
\hline$D L K 1$ & $2,78088 \mathrm{E}-05$ & $-5,78629$ \\
\hline GSTM1 & $6,42006 \mathrm{E}-06$ & $-7,46130$ \\
\hline FOXQ1 & $5,44745 \mathrm{E}-05$ & $-9,50597$ \\
\hline GSTM1 & 3,27945E-07 & $-9,80354$ \\
\hline TMEM119 & $1,61898 \mathrm{E}-06$ & $-13,59590$ \\
\hline
\end{tabular}

expressed and showed a Fold-Change of $>2$ or $<-2$ under conditions of hypergravity of $1.8 \mathrm{~g}$. An enrichment analysis for Gene Ontology (GO) Biological Processes (BP) terms (top 15 given in Table 2, for a complete list see Additional file 1) revealed that mainly development-related processes were detected. GO:0048598 (embryonic morphogenesis, $\mathrm{p}=2.28 \times 10^{-5}$ ), GO:0001501 (skeletal system development, $\mathrm{p}=3.33 \times 10^{-5}$ ), and GO:0048729 (tissue morphogenesis, $\mathrm{p}=3.83 \times 10^{-5}$ ) were the most prominent. However, many genes belonging to these $\mathrm{BP}$ are also implicated in cartilage development (GO:0051216, $\mathrm{p}=5.59 \times 10^{-4}$ ) or cell adhesion (GO:0007155, $\mathrm{p}=5.96 \times 10^{-4}$ ) and biological adhesion (GO:0022610, $\left.\mathrm{p}=6.05 \times 10^{-4}\right)$, such as the bone morphogenetic protein 4 (BMP4), fibroblast growth factor 9 (FGF9), 
Table 2 Top 15 significantly enriched Gene Ontology biological processes under hypergravity

\begin{tabular}{|c|c|c|c|}
\hline GO ID & Process & p-value & Genes represented \\
\hline GO:0048598 & embryonic morphogenesis & $2.28^{*} 10^{-5}$ & $\begin{array}{l}\text { BMP4, WNT5A, FGF9, GDF5, EDN1, COL2A1, HOXD10, MSX1, LAMA5, ALDH1A3, } \\
\text { TFAP2A, TXNRD1, FBN2 }\end{array}$ \\
\hline GO:0001501 & skeletal system development & $3.33^{*} 10^{-5}$ & $\begin{array}{l}\text { BMP4, WNT5A, AEBP1, FGF9, TUFT1, EDN1, COL2A1, DLK1, HOXD10, HOXC8, } \\
\text { MSX1, TFAP2A, GPNMB }\end{array}$ \\
\hline GO:0048729 & tissue morphogenesis & $3.83^{*} 10^{-5}$ & BMP4, FOXQ1, CRYGS, PGF, LAMA5, ALDH1A3, TGM3, TFAP2A, TXNRD1, CA2 \\
\hline GO:0048736 & appendage development & $4.16^{*} 10^{-5}$ & WNT5A, MSX1, MEOX2, FGF9, GDF5, COL2A1, FBN2, HOXD10 \\
\hline GO:0060173 & limb development & $4.16^{*} 10^{-5}$ & WNT5A, MSX1, MEOX2, FGF9, GDF5, COL2A1, FBN2, HOXD10 \\
\hline GO:0035295 & tube development & $1.79^{*} 10^{-4}$ & WNT5A, BMP4, FGF9, PGF, LAMA5, EDN1, HOPX, TFAP2A, HHIP, CXCL12 \\
\hline GO:0035107 & appendage morphogenesis & $2.81 * 10^{-4}$ & WNT5A, MSX1, FGF9, GDF5, COL2A1, FBN2, HOXD10 \\
\hline GO:0035108 & limb morphogenesis & $2.81^{*} 10^{-4}$ & WNT5A, MSX1, FGF9, GDF5, COL2A1, FBN2, HOXD10 \\
\hline GO:0002009 & morphogenesis of an epithelium & $3.13^{*} 10^{-4}$ & BMP4, CRYGS, PGF, LAMA5, ALDH1A3, TFAP2A, CA2 \\
\hline GO:0001525 & angiogenesis & $4.01^{*} 10^{-4}$ & BMP4, MEOX2, FGF9, PGF, LAMA5, EDN1, CXCL12, ANGPTL4 \\
\hline GO:0060541 & respiratory system development & $4.49^{*} 10^{-4}$ & WNT5A, BMP4, FGF9, LAMA5, ALDH1A3, HOPX, HHIP \\
\hline GO:0051216 & cartilage development & $5.59^{*} 10^{-4}$ & WNT5A, BMP4, MSX1, FGF9, EDN1, COL2A1 \\
\hline GO:0007155 & cell adhesion & $5.96^{*} 10^{-4}$ & $\begin{array}{l}\text { HAPLN1, AEBP1, EPDR1, CPXM2, COL2A1, CDH2, EMILIN2, CXCL12, OMD, PGM5, } \\
\text { LAMA5, ITGB1BP1, MSLN, LAMC2, GPNMB, THBS2, NTM }\end{array}$ \\
\hline GO:0022610 & biological adhesion & $6.05^{*} 10^{-4}$ & $\begin{array}{l}\text { HAPLN1, AEBP1, EPDR1, CPXM2, COL2A1, CDH2, EMILIN2, CXCL12, OMD, PGM5, } \\
\text { LAMA5, ITGB1BP1, MSLN, LAMC2, GPNMB, THBS2, NTM }\end{array}$ \\
\hline GO:0048514 & blood vessel morphogenesis & $6.81 * 10^{-4}$ & BMP4, MEOX2, FGF9, PGF, LAMA5, EDN1, CDH2, CXCL12, ANGPTL4 \\
\hline
\end{tabular}

hyaluronan and proteoglycan link protein 1 (HAPLN1), collagen type $2 \alpha 1$ (COL2A1), or laminin $\alpha 5$ (LAMA5).

\section{Influence of vibration on chondrocyte gene expression}

Selected genes were analysed by quantitative real-time PCR. After 2 hours of vibration, gene expression of interleukin-6 (IL6, Figure 1B) and -8 (IL8, Figure 1D), were significantly elevated, while epidermal growth factor (EGF, Figure $1 \mathrm{E}$ ), vascular endothelial growth factor $\mathrm{D}$ (VEGFD, Figure 1J), and fibroblast growth factor 17 (FGF17, Figure 1K) transcripts were significantly downregulated $(\mathrm{p}<0.05)$. No changes were observed for connective tissue growth factor (CTGF, Figure 1A), caveolin 2 (CAV2, Figure $1 C$ ), protein kinase, AMP-activated, $\alpha 1$ (PRKAA, Figure $1 \mathrm{~F}$ ), vascular endothelial growth factor A (VEGFA, Figure 1G), protein kinase c alpha (PRKCA, Figure $1 \mathrm{H})$, ezrin (VIL2, Figure 1I), and interleukin-15 (IL15, Figure 1L).

\section{Influence of hypergravity and vibration on soluble factor release}

Hypergravity induced a more than 2-fold increase in the release of IL-6 in the supernatant (Figure 2A). IL-8, EGF, VEGFD and FGF17 concentrations in the culture supernatant of hypergravity samples were below the detection limit.

ELISA analysis revealved no significant change in the concentration of IL-6 protein in chondrocytes cultured under conditions of vibration (Figure 2B), whereas IL-8,
EGF, VEGFD and FGF17 concentrations in the culture supernatant were below the detection limit.

\section{Parabolic flight maneuvers induced expression changes in chondrocytes}

The influence of the parabolic flight after $1 \mathrm{P}$ and $31 \mathrm{P}$ was investigated. Shortly, the $1 g$ vs. first parabola (1P) vs. 31st Parabola (31P) set was subjected to an F-test. Resulting significant differential expressed probes ( $5 \%$ FDR) were clustered using $\mathrm{k}=6$. Individual expression characteristics of the 6 clusters are documented in Figure 3.

\section{Influence of the parabolic flight \\ Gene array analysis}

Cluster 1 (Table 3) of the parabolic flight set consists of 112 genes, which were upregulated after both $1 \mathrm{P}$ and 31P. The predominant biological processes (Additional file 1, for all following clusters) which were found to be significantly enriched were mostly transcription- and metabolismrelated (GO:0045449 regulation of transcription, $\mathrm{p}=$ $6.08 \times 10^{-8}$; GO:0051252 regulation of RNA metabolic process, $\mathrm{p}=1.59 \times 10^{-7}$; GO:0006355 regulation of transcription, DNA-dependent, $\mathrm{p}=1.48 \times 10^{-6}$; GO:0006357 regulation of transcription from RNA polymerase II promoter, $\mathrm{p}=8.69 \times 10^{-6}$; GO:0006350 transcription, $\mathrm{p}=$ $1.09 \times 10^{-5}$; GO:0019220 regulation of phosphate metabolic process, $\mathrm{p}=6.90 \times 10^{-5}$ ). Interestingly, there was also anti-apoptosis (GO:0006916, $\mathrm{p}=1.42 \times 10^{-4}$ ), represented by such genes as vascular endothelial growth factor $\mathrm{A}$ 

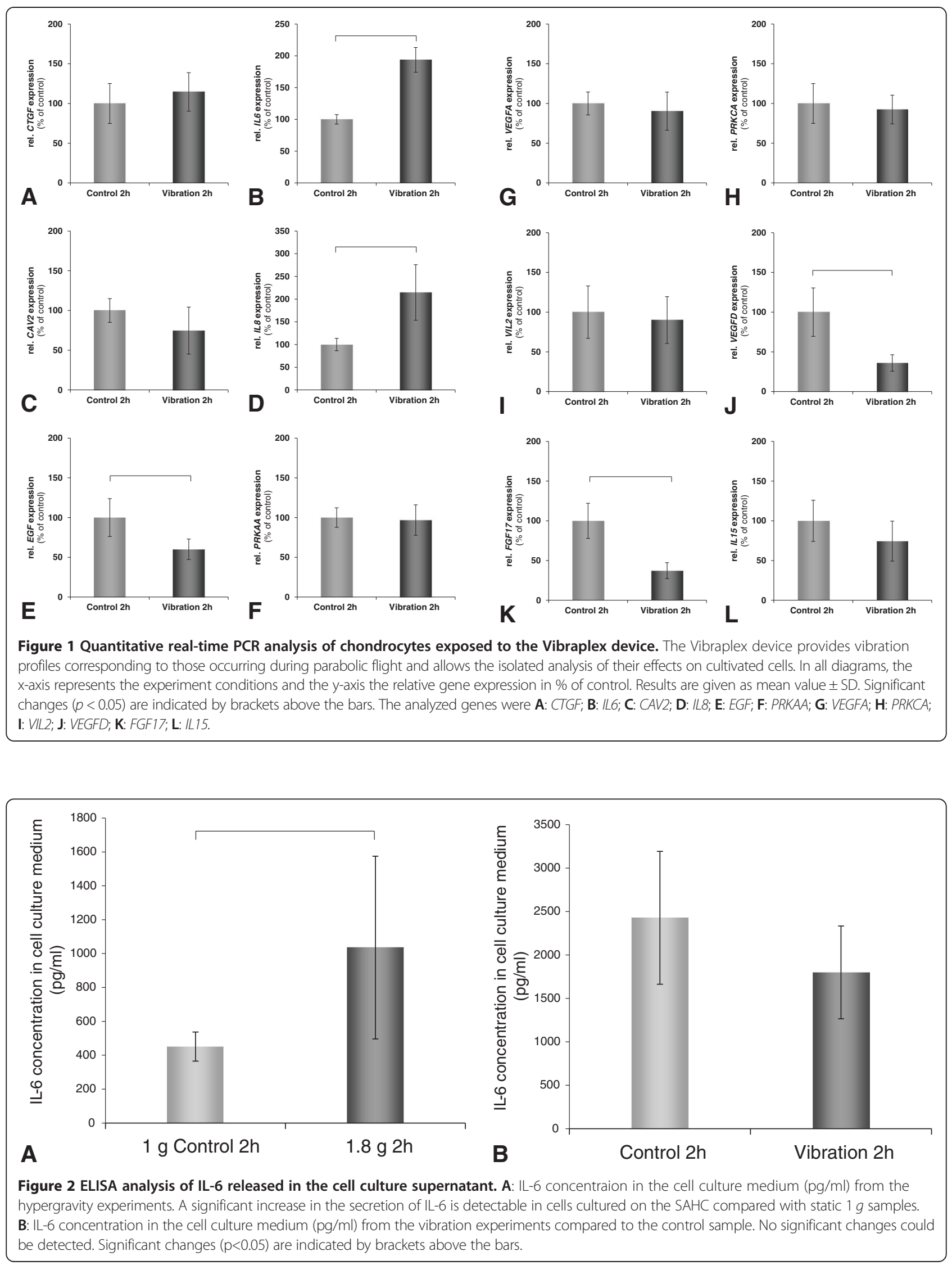


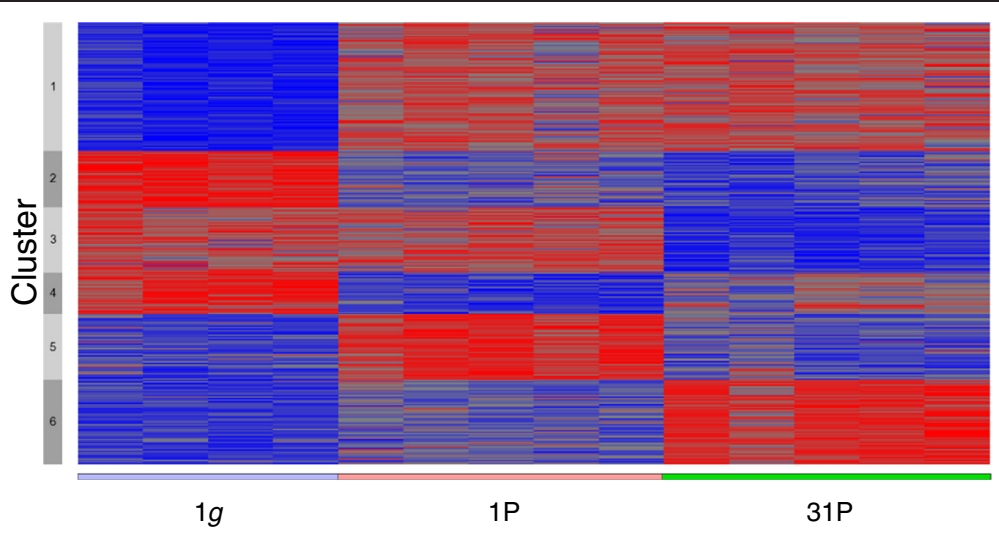

Figure 3 Heatmap showing the clustering of differentially expressed transcripts for the parabolic flight microarray experiments. Analysis after one (1P) and 31 parabolas (31P); red: strong expression; blue: weak expression.

(VEGFA), neurogenic locus notch homolog protein 2 (NOTCH2), or high-mobility group protein B1 (HMGB1).

51 genes were downregulated after 31P showed an intermediate state after 1P constitute cluster 2 (Table 3). Only few significantly enriched BP were identified and their composition resembled cluster 1 with transcriptional (GO:0045449 regulation of transcription, $\mathrm{p}=6.35 \times 10^{-4}$; GO:0006350 transcription, $\mathrm{p}=1.44 \times 10^{-4}$; GO:0006355 regulation of transcription, DNA-dependent, $\mathrm{p}=1.90 \times 10^{-2}$ ), metabolic (GO:0051252 regulation of RNA metabolic process, $\mathrm{p}=2.15 \times 10^{-2}$ ), and developmental (GO:0007498 mesoderm development, $\mathrm{p}=9.48 \times 10^{-3}$ ) processes.

Cluster 3 (Table 3), comprising of 59 genes which were downregulated after 31P, and also showed very few enriched BP, namely GO:0045449 (regulation of transcription, $\mathrm{p}=8.41 \times 10^{-3}$ ), and GO:0006350 (transcription, $\mathrm{p}=$ $1.00 \times 10^{-2}$ ).

Cluster 4 (Table 3) represents 37 genes which were downregulated after $1 \mathrm{P}$ and showed intermediate effects after 31P. No significantly enriched BP was identified.

Cluster 5 (Table 3), consisting of 59 genes upregulated after 1P only, showed BP involved in transcription (GO:0006350 transcription, $\mathrm{p}=2.75 \times 10^{-5}$; GO:0045449 regulation of transcription, $\left.\mathrm{p}=3.01 \times 10^{-5}\right)$, but also regulation of tumor necrosis factor production (GO:0032680, $\mathrm{p}=3.57 \times 10^{-3}$ ) and rhythmic processes (GO:0048511 rhythmic process, $\mathrm{p}=5.90 \times 10-3$; GO:0007623 circadian rhythm, $\mathrm{p}=7.73 \times 10^{-3}$ ).

73 genes were upregulated only after $31 \mathrm{P}$ were pooled into cluster 6 (Table 3). This cluster differs considerably from the other five, as a strong emphasis of (anti)apoptotic BP was observed. Genes such as IL6, IL8, baculoviral IAP repeat-containing protein3 (BIRC3), induced myeloid leukemia cell differentiation protein (MCL1), or TNF receptor-associated factor 1 (TRAF1) lead to the enrichment of BP, such as GO:0006916 (anti-apoptosis, $\mathrm{p}=1.66 \times 10^{-5}$ ), GO:0043066 (negative regulation of apoptosis, $\mathrm{p}=7.39 \times 10^{-5}$ ), GO:0043069 (negative regulation of programmed cell death, $\mathrm{p}=8.15 \times 10^{-5}$, GO:0060548 (negative regulation of cell death, $\mathrm{p}=8.31 \times 10^{-5}$ ), or GO:0006915 (apoptosis, $\left.\mathrm{p}=1.15 \times 10^{-4}\right)($ Figure 4).

\section{Quantitative real-time $P C R$}

In addition to the microarray analysis, we also employed the quantitative real-time PCR technique to validate selected genes of interest. CCNA2 as well as IL8 were significantly upregulated only after 31P (Figure 5A, D). CD44 and TNFA were significantly upregulated only after $1 \mathrm{P}$ (Figure 5B, G). VCAM showed a significant downregulation after 31P (Figure 5E). No effects were observed for IL6, EDN1 and FGF9 (Figure 5C, F, H).

\section{Discussion}

In this study we investigated the effects of short-term real $\mu g$, continuous hypergravity and vibration on human chondrocytes growing in monolayers. For these aims, we employed parabolic flight maneuvers as well as groundbased devices to expose the cells to isolated acceleration profiles and to vibrations as they occur in a combined manner during the flight conditions.

\section{Short-term hypergravity affects chondrocytes}

The microarray analysis of chondrocytes exposed for $2 \mathrm{~h}$ to $1.8 \mathrm{~g}$ revealed that only a very moderate amount of genes was affected in comparison to the parabolic flight effects. It is interesting to notice, that mainly biological processes were affected, which are involved in tissue morphogenesis or skeletal system development. This is a strong indication, that hypergravity directly affects cartilage development.

It has recently been shown, that mechanical load can induce vascular endothelial growth factor A (VEGF-A) expression [21]. VEGF-A belongs to a family of growth factors comprising VEGF-A, $-\mathrm{B},-\mathrm{C},-\mathrm{D},-\mathrm{E}$, and placenta growth factor (PGF) $[22,23]$ and is one of the key components to control angiogenesis, the development of new 


\begin{tabular}{|c|c|c|c|c|}
\hline Cluster & GO ID & Process & p-value & Genes represented \\
\hline \multirow[t]{5}{*}{1} & GO:0045449 & regulation of transcription & $6.08 * 10^{-8}$ & $\begin{array}{l}\text { HMGB1, SBNO2, ELF4, FOXO1, NFKB2, TRIB1, LIF, TSC22D1, HEXIM1, ZNF697, } \\
\text { PER2, SIK1, SERTAD2, NFATC1, MAFG, BMP2, EGR2, CEBPB, KLF9, KLF13, RELB, } \\
\text { LOC100131261, PURB, FOXN3, SOD2, PTHLH, NOTCH2, PHF1, ETS1, JMJD6, } \\
\text { VEGFA, ERN1, FOXC2, HABP4, ZBTB2, NCOR2 }\end{array}$ \\
\hline & GO:0051252 & $\begin{array}{l}\text { regulation of RNA metabolic } \\
\text { process }\end{array}$ & $1.59^{*} 10^{-7}$ & $\begin{array}{l}\text { HMGB1, SBNO2, ELF4, FOXO1, MAPKAPK2, NFKB2, LIF, TSC22D1, HEXIM1, } \\
\text { PER2, SIK1, NFATC1, SERTAD2, MAFG, BMP2, EGR2, CEBPB, KLF9, KLF13, } \\
\text { RELB, FOXN3, PURB, SOD2, NOTCH2, JMJD6, ETS1, VEGFA, FOXC2, NCOR2 }\end{array}$ \\
\hline & GO:0006355 & $\begin{array}{l}\text { regulation of transcription, } \\
\text { DNA-dependent }\end{array}$ & $1.48^{*} 10^{-6}$ & $\begin{array}{l}\text { HMGB1, SBNO2, ELF4, FOXO1, NFKB2, LIF, TSC22D1, HEXIM1, PER2, SIK1, } \\
\text { NFATC1, SERTAD2, MAFG, BMP2, EGR2, CEBPB, KLF9, KLF13, RELB, FOXN3, } \\
\text { PURB, SOD2, NOTCH2, ETS1, VEGFA, FOXC2, NCOR2 }\end{array}$ \\
\hline & GO:0006357 & $\begin{array}{l}\text { regulation of transcription from } \\
\text { RNA polymerase II promoter }\end{array}$ & $8.69^{*} 10^{-6}$ & $\begin{array}{l}\text { HMGB1, BMP2, EGR2, CEBPB, KLF9, ELF4, KLF13, FOXO1, SOD2, LIF, ETS1, } \\
\text { HEXIM1, VEGFA, FOXC2, SIK1, NCOR2 }\end{array}$ \\
\hline & GO:0006350 & transcription & $1.09 * 10^{-5}$ & $\begin{array}{l}\text { SBNO2, ELF4, FOXO1, NFKB2, TSC22D1, HEXIM1, ZNF697, PER2, NFATC1, } \\
\text { SERTAD2, MAFG, EGR2, CEBPB, KLF9, KLF13, RELB, FOXN3, LOC100131261, } \\
\text { PURB, NOTCH2, PHF1, JMJD6, ETS1, ERN1, HABP4, FOXC2, ZBTB2, NCOR2 }\end{array}$ \\
\hline \multirow[t]{5}{*}{2} & GO:0045449 & regulation of transcription & $6.34 * 10^{-4}$ & $\begin{array}{l}\text { TXNIP, ZNF84, RCOR2, PPM1A, NFYA, ZNF514, ZNF512, MEN1, LHX2, ZNF239, } \\
\text { ZNF471, ZNF599, THAP11, RNF14 }\end{array}$ \\
\hline & GO:0006350 & transcription & $1.44^{*} 10^{-3}$ & $\begin{array}{l}\text { TXNIP, ZNF84, RCOR2, LHX2, ZNF239, ZNF471, ZNF599, NFYA, ZNF514, } \\
\text { THAP11, ZNF512, RNF14 }\end{array}$ \\
\hline & GO:0007498 & mesoderm development & $9.48^{*} 10^{-3}$ & NUP133, OSR1, LHX2 \\
\hline & GO:0006355 & $\begin{array}{l}\text { regulation of transcription, } \\
\text { DNA-dependent }\end{array}$ & $1.90^{*} 10^{-2}$ & MEN1, ZNF84, LHX2, PPM1A, ZNF471, ZNF599, NFYA, ZNF514, RNF14 \\
\hline & GO:0051252 & $\begin{array}{l}\text { regulation of RNA metabolic } \\
\text { process }\end{array}$ & $2.16^{*} 10^{-2}$ & MEN1, ZNF84, LHX2, PPM1A, ZNF471, ZNF599, NFYA, ZNF514, RNF14 \\
\hline \multirow[t]{2}{*}{3} & GO:0045449 & regulation of transcription & $8.41 * 10^{-3}$ & $\begin{array}{l}\text { DPF2, ZBTB22, EID2B, ZNF451, ZNF25, BANP, ZKSCAN1, ZNF514, UBN1, } \\
\text { NR2C1, PIAS4, PRMT6, BAZ2B, TIGD7, IRAK1BP1 }\end{array}$ \\
\hline & GO:0006350 & transcription & $1.01 * 10^{-2}$ & $\begin{array}{l}\text { DPF2, ZBTB22, EID2B, ZNF451, ZNF25, BANP, ZKSCAN1, ZNF514, NR2C1, } \\
\text { PIAS4, PRMT6, BAZ2B, IRAK1BP1 }\end{array}$ \\
\hline 4 & None & & & \\
\hline \multirow[t]{5}{*}{5} & GO:0006350 & transcription & $2.75^{*} 10^{-5}$ & $\begin{array}{l}\text { ERF, EGR3, ELL, NR4A2, C14ORF43, ZNF16, MEF2D, CRY2, NAB2, MNT, } \\
\text { SERTAD3, BCL3, PER1, RARA, VGLL4, CHD6, NFIL3, SERTAD1 }\end{array}$ \\
\hline & GO:0045449 & regulation of transcription & $3.01 * 10^{-5}$ & $\begin{array}{l}\text { ERF, EGR3, ELL, NR4A2, ZNF16, C14ORF43, DLX3, MEF2D, CRY2, ID1, } \\
\text { NAB2, MNT, SERTAD3, BCL3, PER1, RARA, VGLL4, CHD6, NFIL3, SERTAD1 }\end{array}$ \\
\hline & GO:0032680 & $\begin{array}{l}\text { regulation of tumor necrosis } \\
\text { factor production }\end{array}$ & $3.57^{*} 10^{-3}$ & NOD1, BCL3, RARA \\
\hline & GO:0048511 & rhythmic process & $5.90^{*} 10^{-3}$ & EGR3, CRY2, PER1, NFIL3 \\
\hline & GO:0007623 & circadian rhythm & $7.74 * 10^{-3}$ & EGR3, CRY2, PER1 \\
\hline \multirow[t]{5}{*}{6} & GO:0006916 & anti-apoptosis & $1.66^{*} 10^{-5}$ & CSF2, IER3, MCL1, HIPK3, NFKBIA, ILIB, TNFAIP3, BIRC3 \\
\hline & GO:0043066 & negative regulation of apoptosis & $7.39 * 10^{-5}$ & CSF2, IER3, IL6, MCL1, HIPK3, NFKBIA, ILIB, TNFAIP3, BIRC3 \\
\hline & GO:0043069 & $\begin{array}{l}\text { negative regulation of programmed } \\
\text { cell death }\end{array}$ & $8.15^{*} 10^{-5}$ & CSF2, IER3, IL6, MCL1, HIPK3, NFKBIA, ILIB, TNFAIP3, BIRC3 \\
\hline & GO:0060548 & negative regulation of cell death & $8.31^{*} 10^{-5}$ & CSF2, IER3, IL6, MCL1, HIPK3, NFKBIA, ILIB, TNFAIP3, BIRC3 \\
\hline & GO:0006915 & apoptosis & $1.15^{*} 10^{-4}$ & $\begin{array}{l}\text { TRAF1, RNF144B, IER3, IL6, MCL1, HIPK3, NFKBIA, IL1B, ZC3H12A, TNFAIP3, } \\
\text { BIRC3 }\end{array}$ \\
\hline
\end{tabular}

vessels from existing ones. VEGF is predominantly found in osteoarthritic cartilage/chondrocytes and contributes further to the disintegration of the cartilage by inducing matrix metalloproteinases, which are able to disrupt the extracellular matrix [24,25]. We have observed a similar tendency for VEGFA gene expression, which was significantly elevated by a factor of 1.65 , but was omitted for the
GO BP analysis due to our cut-off of a Fold-Change $>2$. Interestingly, $M M P 3$ and $M M P 10$ transcripts were downregulated under hypergravity. We speculate that this might be due to the fact that the chondrocytes form a monolayer in the culture flasks and are not embedded in an ECM-like matrix as in their physiological environment. This strong MMP downregulation might therefore be an 


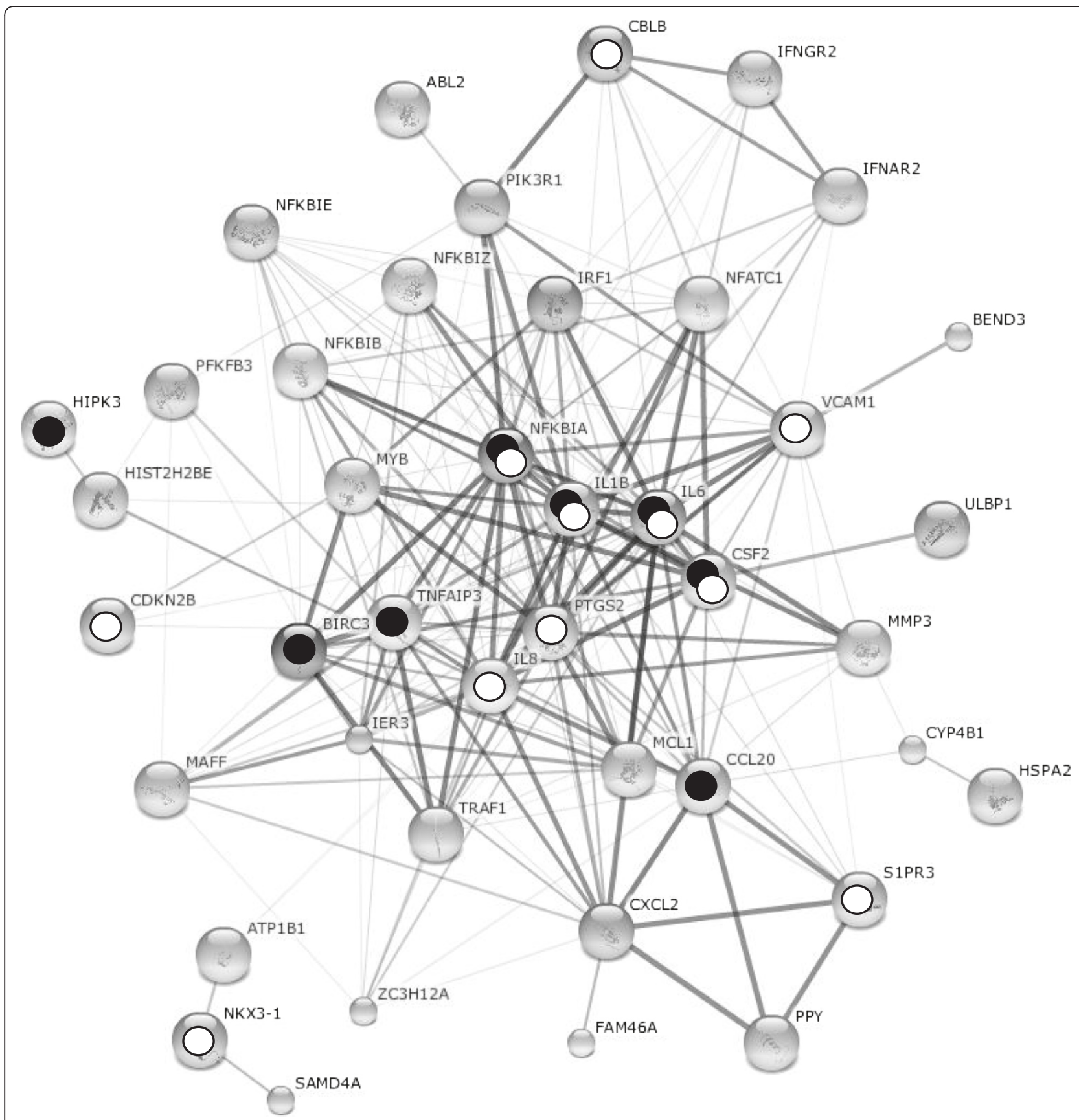

Figure 4 STRING analysis of the cluster 6 from the parabolic flight experiment. Chondrocytes were fixed after parabola 1 and 31 during a parabolic flight. In parallel, corresponding $1 \mathrm{~g}$ control samples were prepared. K-mean clustering of the resulting microarray data revealed 6 clusters of differentially expressed genes. Clusters 1-5 revealed mostly unspecific transcriptionally active genes, while cluster 6 showed a strong dominance by anti-apoptotic and cell-proliferative transcripts. Possible interactions of the corresponding proteins were visualized using the STRING software and genes involved in anti-apoptosis and cell proliferation were highlighted with white and black circles, respectively.

attempt to build up a thick ECM, and a stronger stimulus than the VEGFA induction.

$B M P 4$, on the other hand, coding for the bone morphogenetic protein 4 (BMP-4; Additional file 1) was found to be downregulated under hypergravity. BMP-4 stimulates the synthesis of collagen type 2 and aggrecan and thus, enhaces the production of articular cartilage [26,27]. EDN1 (endothelin 1) gene expression was observed to be enhanced (Additional file 1). It has been reported, that overexpression of endothelin 1 is associated with cartilage degeneration [28]. In contrast to this, the inhibitor of apoptosis, BIRC3 (Additional file 1) [29], was enhanced 


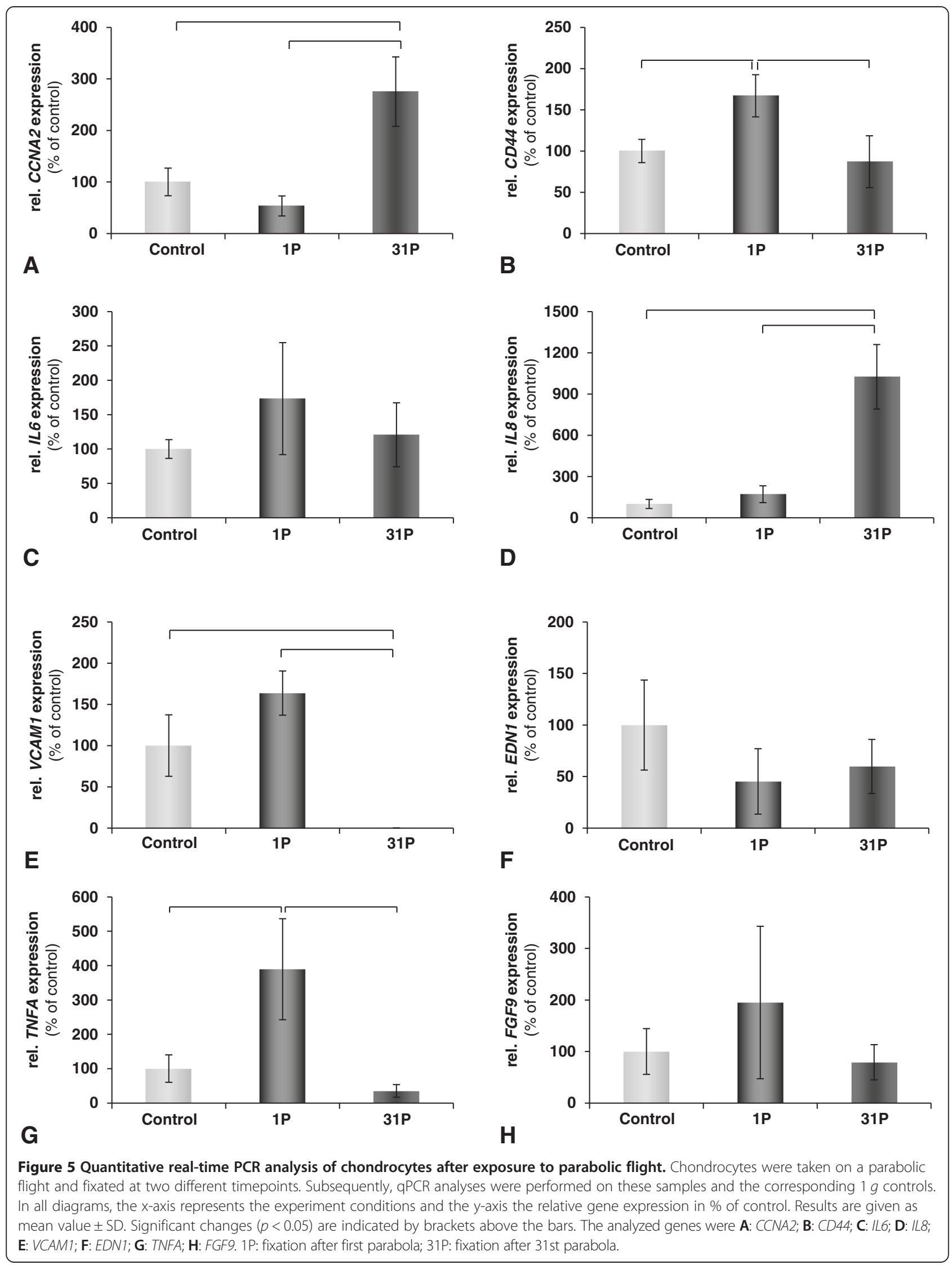


hinting towards an improved cell survival. Furthermore, the gene expression of wingless-type MMTV integration site family, member 5A (WNT5A) was decreased (Additional file 1). Wnt-5a has been shown to be able to induce cartilage degradation through upregulation of MMPs [30]. All in all, it is obvious that in our setup chondrocytes are sensitive to mechanical stress by hypergravity, but at the moment, no definite answer can be given about the nature of the effect.

\section{Short-term vibration is detrimental to chondrocytes}

In contrast to hypergravity, the effects of vibration on cultured chondrocytes were clearer. In our experimental setup, the vibrations which were transmitted into the culture flask also caused the culture medium to stir to a certain dregree, which, as we speculate, resulted in additional shear forces. Shear forces have been shown to have a negative effect on chondrocytes and cartilage [31,32]. It has been reported, that cartilage, that was treated in such a way or was degenerating, produced increased amounts of proinflammatory interleukins, such as IL-6 or IL-8 [33,34]. In our qPCR analysis we found a strong increase of both IL6 and IL8 (Figure $1 \mathrm{~B}+\mathrm{D}$ ) gene expression, although no increase in IL-6 secretion (Figure 2), accompanied by decreases of EGF, VEGFD, and FGF17 (Figure 1E, J, K) gene expression. The presence of these factors has been described as beneficial for cartilage development $[35,36]$. Taken together, our results indicate that vibration drives chondrocytes towards an inflammatory, cartilage destabilzing state.

\section{The influence of parabolic flight maneuvers}

The microarray analysis showed, that after only 1P relatively unspecific effects on the cells were observed, mainly connected to transcription. This is an indication that the cells have perceived the change in gravity and that they were preparing their transcriptional apparatus for an altered gene expression as a reaction to this stimulus. After 31P, we observed an increase in the enrichment of antiapoptotic genes. The qPCR analysis reflects the same tendency. Most of the investigated genes showed only transitional or no changes, such as CD44, IL6, EDN1, TNFA, and FGF9 (Figure 5B, C, F, G, H). This seems to hint toward a short $\mu g$ "shock" that the cells are able to overcome very quickly. Only CCNA2 (Figure 5A), a cyclin involved in cell cycling and proliferaton [37] and the antiapoptotic IL8 (Figure 5D) [38] are expressed in a manner that they exert a growth-promoting, cell-survival effect. It should be kept in mind, that these effects originate from only a short-term altered gravity (PFC) treatment and that longer exposure times have to be investigated in order to assess their significance. It is interesting to note that RPM exposure experiments resulted in increased expression of several genes responsible for cell motility, structure and integrity; control of cell growth, cell proliferation, cell differentiation and apoptosis [39] and that these results are also in very good accordance with earlier studies that also reported that chondrocytes are quite robust under $\mu g$ stress [40].

\section{Conclusions}

We have shown that chondrocytes are very robust under conditions of parabolic flight maneuvers. They are able to adapt quickly to this new environment and actually profit from real $\mu g$ by reducing their apoptotic rate. However, they are prone to damage/injury by hypergravity and especially by vibration/shear forces. All in all, these results are very promising and are a step further along the way to understand chondrocyte growth in $\mu g$, leading perhaps to new methods of scaffold-free preparation of cartilage grafts.

\section{Materials and methods Parabolic flight}

The parabolic flight experiments were conducted aboard the Airbus A300 ZERO-G operated by Novespace and based in Bordeaux-Merignac, France [19,41-43]. Standard parabolic flights were performed, each with 31 parabolas in a row during the three to four hours flight. The flight manoeuver starts from the horizontal flight level followed by a $45^{\circ}$ ascent for $20 \mathrm{~s}$. During this time $1.5 \mathrm{~g}$ to $1.8 \mathrm{~g}$ are acting on the passengers and the experiments. Then the thrust is reduced and the aircraft follows the path of a parabola. The free fall (microgravity) phase starts and persists for $22 \mathrm{~s}$. Afterwards, the engines are fully powered again and another phase of $1.8 \mathrm{~g}$ of $20 \mathrm{~s}$ terminates the parabola. Due to the aerodynamic forces and turbulences acting on the aircraft, the $\mu g$ quality is in the range of about $10^{-2} \mathrm{~g}$.

\section{Cells and cell culture medium}

Commercially available human chondrocytes (Provitro ${ }^{\circ}$, Berlin, Germany) were cultured in Chondrocyte Growth Medium basal (CGM, Provitro ${ }^{\circ}$, Berlin, Germany) supplemented with $10 \%$ fetal calf serum (Provitro ${ }^{\circ}$, Berlin, Germany), $100 \mathrm{IU}$ penicillin/mL and $100 \mu g$ streptomycin/ $\mathrm{mL}$ (Provitro ${ }^{\circ}$, Berlin, Germany).

\section{Cell culture procedure}

Cells were grown as published recently $[19,44]$. Briefly, the cells were cultured in 24 T75 cell culture flasks (75 $\mathrm{cm}^{2}$; Sarstedt, Nümbrecht, Germany) until subconfluent monolayers were obtained. During this time, the cells were covered by $20 \mathrm{~mL}$ (T-75 flasks) CGM. One half of the flasks was used as ground control cells $(1 g$; $\mathrm{n}=12$ ), cultured and fixed further in the laboratory, the other half was taken on the parabolic flight $(n=12)$. During the parabolic flight, RNAlater (Applied Biosystems, Darmstadt, Germany) was injected via syringes containing the appropriate fixative. The syringes were connected to 
the T-75 flasks through a flexible tube and a 3-way-valve. One hour before each flight, the cell culture flasks were transported to the aircraft and placed into the $37^{\circ} \mathrm{C}$ preheated incubator on an experimental rack (Figure 6A).

\section{Cell fixation}

The cells were fixed after the first parabola (1P) and after the 31st parabola (31P) using RNAlater (Applied Biosystems, Darmstadt, Germany) at a ratio of $4: 1$ (RNAlater:medium). After the flight, the fixative was discarded, the cells were briefly washed with PBS and covered with $10 \mathrm{ml}$ of fresh RNAlater. Subsequently, the flasks were stored at $4^{\circ} \mathrm{C}$ and transported to the laboratory. For the quantitative real-time PCR, we collected $\mathrm{n}=6$ T75 cell culture flasks from both parabolic flight samples $(1 \mathrm{P}$ and $31 \mathrm{P})$ and the $1 g$ control group, the remaining flasks were used for microarray analyses.

\section{Hypergravity experiments}

We performed experiments on the Short Arm Human Centrifuge (SAHC, DLR, Cologne, Germany) (Figure 6B), with cells cultured in T75 cell culture flasks $\left(75 \mathrm{~cm}^{2}\right.$; Sarstedt, Nümbrecht, Germany), growing in a monolayer. We installed two containers with floating mountings for the incubators on the SAHC (Figure 6C). In this configuration the T75 cell culture flasks were always exposed to a correct vertical gravity (acceleration) vector during centrifugation. By using the power supply on the SAHC the incubators were constantly heated to $37^{\circ} \mathrm{C}$.
On the SAHC, we exposed the samples to a continuous hypergravity phase of $1.8 \mathrm{~g}$ of about 2 hours corresponding to the total time frame of 31 parabolas.

We designed a homogenous centrifuge profile with constant spin-up and spin-down times of each 34 seconds.

We collected $\mathrm{n}=5$ static $1 \mathrm{~g}$ controls and $\mathrm{n}=51.8 \mathrm{~g}$ hyper- $g$ samples for the Microarray analysis. The $1 g$ controls were cultivated in parallel in a neighboring identical incubator. Immediately after the run, the culture medium was discarded and replaced with $25 \mathrm{~mL}$ RNAlater solution. For the measurement of cytokines released in the supernatant, an additional run of the SAHC was performed to obtain $\mathrm{n}=12$ static $1 \mathrm{~g}$ samples and $\mathrm{n}=12$ 1.8 hyper- $g$ samples for the ELISA technique.

\section{Vibration experiments}

The detailed method was published earlier [20]. In short, the Vibraplex vibration platform (frequency range $0.2 \mathrm{~Hz}$ $14 \mathrm{kHz}$ ) was used to create vibrations comparable to those occurring during parabolic flights (Figure 6D). Corresponding vibrations to the three phases of pull-up (1.8g), free fall $(\mu g)$, and pull-out $(1.8 g)$ were recorded and analysed by Schmidt [45]. These data were then used for the simulation experiments with the Vibraplex. For quantitative real-time PCR analyses, we collected $n=5$ samples of each of the two groups ( $1 g$ controls and cells subjected to a vibration profile corresponding to 31 parabolas of a parabolic flight). The $1 g$ controls without vibration were grown separately in a similar incubator.

For the measurement of cytokines released in the supernatant, three additional vibration experiments were
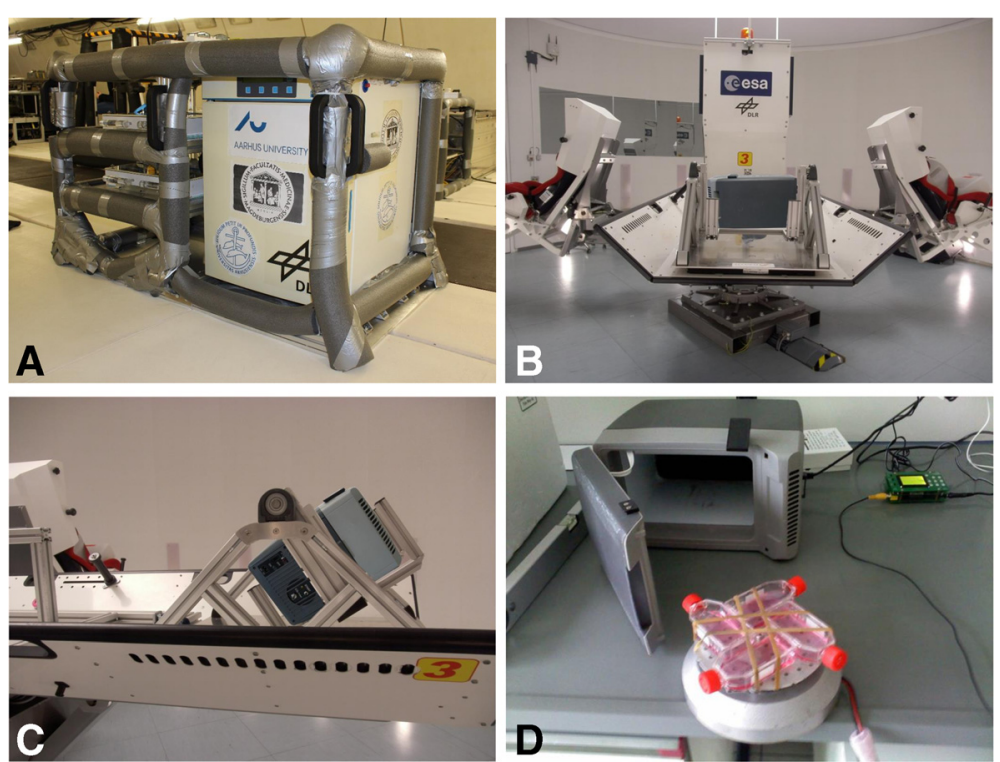

Figure 6 Overview of the facilities used to expose cells to parabolic flight, hypergravity, and vibration. A: The parabolic flight experimental rack; B: The Short Arm Human Centrifuge (SAHC) at the DLR, Cologne, Germany; C: Transportable incubator mounted on the SAHC; D: The Vibraplex device with T25 cell culture flasks mounted on it. 
performed to obtain $\mathrm{n}=12$ static $1 \mathrm{~g}$ samples and $\mathrm{n}=12$ vibrated samples for the ELISA technique.

\section{RNA isolation and CDNA synthesis}

After arrival in the laboratory, the RNAlater solution on the fixed cells was replaced by PBS (Invitrogen, Darmstadt, Germany). The cells were scraped off using cell scrapers (Sarstedt, Nümbrecht, Germany), transferred to $50 \mathrm{ml}$ tubes, and pelleted by centrifugation $(2500 \mathrm{~g}$ for $10 \mathrm{~min}$ at $4^{\circ} \mathrm{C}$ ). An RNeasy Mini Kit (Qiagen, Hilden, Germany) was used according to the manufacturer's instructions to isolate total RNA. RNA concentrations and quality were determined spectrophotometrically at $260 \mathrm{~nm}$ using an Ultrospec 2100 pro Spectrophotometer (Amersham Biosciences, Freiburg, Germany). The isolated RNA had an A260/280 ratio of $>1.7$. cDNA designated for the quantitative real-time PCR was then obtained with the FirstStrand cDNA Synthesis Kit (Fermentas, St. Leon-Rot, Germany) using $1 \mu \mathrm{g}$ of total RNA in a $20-\mu \mathrm{L}$ reverse transcription reaction mixture.

\section{Quantitative real-time PCR}

Quantitative real-time PCR was used to determine the expression levels of the genes of interest. Primer Express software (Applied Biosystems) was applied to design appropriate primers with a $\mathrm{T}_{\mathrm{m}}$ of $\sim 60^{\circ} \mathrm{C}$ (Additional file 2). The primers were synthesized by TIB Molbiol (Berlin, Germany). All assays were run on a StepOnePlus RealTime PCR System using the Power SYBR Green PCR Master Mix (both Applied Biosystems). The reaction volume was $25 \mu \mathrm{L}$ including $1 \mu \mathrm{L}$ of template cDNA and a final primer concentration of $500 \mathrm{nM}$. PCR conditions were as follows: $10 \mathrm{~min}$ at $95^{\circ} \mathrm{C}, 40$ cycles of $30 \mathrm{~s}$ at $95^{\circ} \mathrm{C}$ and $1 \mathrm{~min}$ at $60^{\circ} \mathrm{C}$, followed by a melting curve analysis step (temperature gradient from 60 to $95^{\circ} \mathrm{C}$ with $+0.3^{\circ} \mathrm{C} /$ cycle).

If all amplicons showed one single $\mathrm{T}_{\mathrm{m}}$ similar to the one predicted by Primer Express software, the PCR reactions were considered specific. Every sample was measured in triplicate, and relative quantification was effected by means of the comparative $\mathrm{C}_{\mathrm{T}}\left(\Delta \Delta \mathrm{C}_{\mathrm{T}}\right)$ method. 18S rRNA was used as a housekeeping gene to normalize the expression data.

\section{ELISA}

ELISAs of IL-6, IL-8, EGF, VEGFD (R\&D Systems), and FGF17 (USCN Life Science Inc.) in the cell culture supernatant from vibration and hypergravity experiments have been performed according to the protocols supplied by the manufacturer.

\section{Microarray analysis}

Prior to the analysis, RNA integrity (RIN) was checked with the bioanalyzer. Only samples meeting the required
Table 4 Microarray analyses: projects, samples and conditions

\begin{tabular}{ll}
\hline Experiment & Conditions (Replicates) \\
\hline Hyper-g & Two Conditions: $1 \mathrm{~g}$ controls $(\mathrm{N}=5)$ and $1.8 \mathrm{~g}(\mathrm{~N}=4)$ \\
PFC & $1 \mathrm{~g}$ control $(\mathrm{N}=4), 1$ parabola $(\mathrm{N}=5), 31$ parabola \\
& $(\mathrm{N}=5+1$ outlier $)$ \\
\hline
\end{tabular}

quality were included in the analysis. The Illumina HumanWG-6_V2_0_R3 arrays have been normalized using the BeadStudio Gene Expression Module v3.3.7 and quantile normalization without background correction. After quantile normalization and exclusion of low or not expressed genes (minimum Illumina detection p-value > 0.05 ; performed in both analyses separately) the quality of arrays and the general expression profile has been checked by Principal Component Analysis (PCA) using Partek Genomic Suite 6.6, correlation as a dispersion matrix and normalized Eigenvector scaling. No obvious batch effect or outlier was found for the hypegravity analysis, while the outlying general expression profile of one sample from the parabolic flight experiment was removed before test statistic (for an overview: see Table 4).

A parametric ANOVA comparing the conditions given in Table 5 was performed. The selection criteria for the significant differential expression are also given in Table 2. Differentiation of the expression profiles was performed using K-Mean clustering. The cluster analysis was done using Partek Genomic Suite 6.3 applying the Euclidean distance function on standardized $\log 2$ signal values. $\mathrm{K}$ was selected according to a local minimum of the Davies Bouldin $\mathrm{K}$ estimation procedure. Functional aspects of the differentially expressed probes were analyzed with g: Profiler using g: SCS threshold as significance criterion and the DAVID Bioinformatics Resources 6 [46,47]. Physical and functional interactions between proteins were determined using the String platform [48] at a low confidence score of 0.15 .

\section{Statistical analysis}

All statistical analyses were performed using SPSS 16.0 software (SPSS, Inc., Chicago, IL, USA). We used either 1-way ANOVA or the Mann-Whitney U test. Differences were considered significant at the level of $\mathrm{P}<0.05$. All data are presented as means \pm SD.

Table 5 Microaray analyses: comparisons

\begin{tabular}{lll}
\hline Experiment & Comparisons & $\begin{array}{l}\text { Significance } \\
\text { criterion used }\end{array}$ \\
\hline Hyper-g & two way ANOVA(gravity vs. plate): & $5 \%$ FDR \\
& $1 \mathrm{~g}$ controls and $1.8 \mathrm{~g}$ & \\
PFC & ANOVA (parabola) $1 \mathrm{~g}$ control, & $5 \% \mathrm{FDR}$ \\
& 1 parabola, 31 parabolas & \\
\hline
\end{tabular}




\section{Additional files}

\section{Additional file 1: This file provides expanded versions of Tables 1 and 2 as well as the complete overview of the GO BP analysis of the microaray data.}

Additional file 2: Primers used for quantitative real-time PCR. All sequences are given in 5'-3' direction.

\begin{abstract}
Abbreviations
BIRC3: Baculoviral IAP repeat-containing protein3; BMP: Bone morphogenetic protein; BP: Biological processes; CASP: Caspase; CAV: Caveolin;

CGM: Chondrocyte growth medium; COL2A1: Collagen type 2 a 1;

CTGF: Connective tissue growth factor; ECM: Extracellular matrix;

EDN1: Endothelin 1; EGF: Epidermal growth factor; ELISA: Enzyme-linked immunosorbent assay; FCS: Fetal calf serum; FDR: False discovery rate; FGF: Fibroblast growth factor; FKBP1A: Peptidyl-prolyl cis-trans isomerase; FTC: Follicular thyroid cancer; GO: Gene Ontology; HAPLN1: Hyaluronan and proteoglycan link protein 1; HMGB1: High-mobility group protein B1; IL: Interleukin; ITBG1: Integrin beta 1; LAMA5: Laminin a 5; $\mu g$ : Microgravity; MCL1: Induced myeloid leukemia cell differentiation protein; MMP: Matrix metalloproteinase; mRNA: Messenger ribonucleic acid; NOTCH2: Neurogenic locus notch homolog protein 2; NR4A2: Nuclear receptor subfamily 4, group A, member 2; P: Parabola; PCA: Principal component analysis; PCR: Polymerase chain reaction; PGF: Placenta growth factor; PRKAA1: Protein kinase, AMP-activated, a 1; PRKCA: Protein kinase c a; PS: Parabola set; SAHC: Short arm human centrifuge; SD: Standard deviation; SOCS3: Suppressor of cytocine signaling 3; TBS: Treated parabola set; TNF: Tumor necrosis factor; TRAF1: TNF receptor-associated factor 1; RPM: Random positioning machine; TNFAIP3: TNF a-induced protein 3; TNFRSF14: TNF receptor superfamily member 14; VEGF: Vascular endothelial growth factor; VIL2: Ezrin; WNT5A: Wingless-type MMTV integration site family, member $5 \mathrm{~A}$.
\end{abstract}

\section{Competing interests}

The authors declare that they have no competing interests.

\section{Authors' contributions}

$\mathrm{DG}, \mathrm{Ml}$ and $\mathrm{RH}$ designed the study. MW, EW, MB, JP, XM, GA, TJC, and SR attended the parabolic flight mission and performed the flight experimens. MW and DG drafted the manuscript. MW, GA, TJC and DG supervised and supported the ground-based experiments. DG, RH and TF supervised the ground-based experiments in Cologne and supported the SAHC and Vibraplex experiments. KS, NH and HS performed the Gene Array analysis and the bioinformatics. XM performed the qPCR. All authors read and approved the final manuscript.

\section{Acknowledgements}

The study was supported by the German Aerospace Center (DLR; BMWi grant 50WB1124; D.G.). Ganna Aleshcheva and Elisabeth Warnke are doctoral candidates of the Helmholtz Space Life Sciences Research School, German Aerospace Center Cologne, Germany.

\section{Author details}

${ }^{1}$ Clinic for Plastic, Aesthetic and Hand Surgery, Otto-von-Guericke University, 39120 Magdeburg, Germany. ${ }^{2}$ Max-Delbrück-Center for Molecular Medicine, 13092 Berlin, Germany. ${ }^{3}$ University of Cologne, Cologne Center for Genomics (CCG), 50931 Cologne, Germany. ${ }^{4}$ DLR German Aerospace Center, Biomedical Research, Gravitational Biology, 51147 Köln, Germany. ${ }^{5}$ Institute for Molecular Physiology and Biotechnology of Plants (IMBIO), University of Bonn, Gravitational Biology Group, 53115 Bonn, Germany. ${ }^{6}$ Department of Biomedicine, Aarhus University, Wilhelm Meyers Allé 4, DK-8000 Aarhus C, Denmark. ${ }^{7}$ German Aerospace Center (DLR), Institute of Aerospace Medicine, Biomedical Research, 51147 Köln, Germany.

Received: 13 November 2014 Accepted: 2 March 2015

Published online: 20 March 2015

\section{References}

1. Poole AR, Kojima T, Yasuda T, Mwale F, Kobayashi M, Laverty S. Composition and structure of articular cartilage: a template for tissue repair. Clin Orthop Relat Res. 2001;391(Suppl):S26-33.

2. Aigner $\mathrm{T}$, Stöve J. Collagens-major component of the physiological cartilage matrix, major target of cartilage degeneration, major tool in cartilage repair. Adv Drug Deliv Rev. 2003;55:1569-93.

3. Wiberg C, Klatt AR, Wagener R, Paulsson M, Bateman JF, Heinegård D, et al. Complexes of matrilin-1 and biglycan or decorin connect collagen VI microfibrils to both collagen II and aggrecan. J Biol Chem. 2003;278:37698-704.

4. Tetlow LC, Adlam DJ, Woolley DE. Matrix metalloproteinase and proinflammatory cytokine production by chondrocytes of human osteoarthritic cartilage: associations with degenerative changes. Arthritis Rheum. 2001;44:585-94.

5. Clements KM, Flannelly JK, Tart J, Brockbank SM, Wardale J, Freeth J, et al. Matrix metalloproteinase 17 is necessary for cartilage aggrecan degradation in an inflammatory environment. Ann Rheum Dis. 2011;70:683-9.

6. Loeser RF. Aging and osteoarthritis: the role of chondrocyte senescence and aging changes in the cartilage matrix. Osteoarthr Cart. 2009;17:971-9.

7. Young AA, Smith MM, Smith SM, Cake MA, Ghosh P, Read RA, et al. Regional assessment of articular cartilage gene expression and small proteoglycan metabolism in an animal model of osteoarthritis. Arthritis Res Ther. 2005;7:R852-61.

8. Alsalameh S, Amin R, Gemba T, Lotz M. Identification of mesenchymal progenitor cells in normal and osteoarthritic human articular cartilage. Arthritis Rheum. 2004;50:1522-32.

9. Zayzafoon M, Meyers VE, McDonald JM. Microgravity: the immune response and bone. Immunol Rev. 2005;208:267-80.

10. Greenwald E, Armstrong K, Leon P, Reinberger K. Growing cartilage in space-Understanding the physiological changes from microgravity. [http://chen2820.pbworks.com/w/page/11951455/Growing\%20cartilage\% 20in\%20space].

11. Stamenković V, Keller G, Nesic D, Cogoli A, Grogan SP. Neocartilage formation in $1 \mathrm{~g}$, simulated, and microgravity environments: implications for tissue engineering. Tissue Eng A. 2010;16:1729-36.

12. Pietsch J, Ma X, Wehland M, Aleshcheva G, Schwarzwälder A, Segerer J, et al. Spheroid formation of human thyroid cancer cells in an automated culturing system during the Shenzhou-8 Space mission. Biomaterials. 2013;34:7694-705.

13. Grosse J, Wehland M, Pietsch J, Schulz H, Saar K, Hübner N, et al. Gravitysensitive signaling drives 3-dimensional formation of multicellular thyroid cancer spheroids. FASEB J. 2012;26:5124-40.

14. Ulbrich C, Wehland M, Pietsch J, Aleshcheva G, Wise P, van Loon J, et al. The impact of simulated and real microgravity on bone cells and mesenchymal stem cells. Biomed Res Int. 2014;2014:928507.

15. Ma X, Wehland M, Schulz H, Saar K, Hübner N, Infanger M, et al. Genomic approach to identify factors that drive the formation of three-dimensional structures by EAhy926 endothelial cells. PLoS One. 2013;8:e64402.

16. Ulbrich C, Westphal K, Pietsch J, Winkler HD, Leder A, Bauer J, et al. Characterization of human chondrocytes exposed to simulated microgravity. Cell Physiol Biochem. 2010;25:551-60.

17. Grimm D, Wehland M, Pietsch J, Aleshcheva G, Wise P, van Loon J, et al. Growing tissues in real and simulated microgravity: new methods for tissue Engineering. Tissue Eng B Rev. 2014;20:555-66.

18. Herranz R, Anken R, Boonstra J, Braun M, Christianen PC, de Geest M, et al. Ground-based facilities for simulation of microgravity: organism-specific recommend-dations for their use, and recommended terminology. Astrobiology. 2013;13:1-17.

19. Aleshcheva G, Wehland M, Sahana J, Bauer J, Corydon TJ, Hemmersbach R, et al. Moderate alterations of the cytoskeleton in human chondrocytes after short-term microgravity produced by parabolic flight maneuvers could be prevented by upregulation of BMP-2 and SOX-9. FASEB J.2015. Feb 13. pii: fj.14-268151. [Epub ahead of print].

20. Wehland M, Ma X, Braun M, Hauslage J, Hemmersbach R, Bauer J, et al. The impact of altered gravity and vibration on endothelial cells during a parabolic flight. Cell Physiol Biochem. 2013;31:432-51.

21. Beckmann R, Houben A, Tohidnezhad M, Kweider N, Fragoulis A, Wruck CJ, et al. Mechanical forces induce changes in VEGF and VEGFR-1/sFlt-1 expression in human chondrocytes. Int J Mol Sci. 2014;15:15456-74.

22. Ferrara N. Role of vascular endothelial growth factor in regulation of physiological angiogenesis. Am J Physiol Cell Physiol. 2001;280:C1358-66 
23. Ferrara N, Gerber HP, LeCouter J. The biology of VEGF and its receptors. Nat Med. 2003:9:669-76.

24. Pufe T, Lemke A, Kurz B, Petersen W, Tillmann B, Grodzinsky AJ, et al. Mechanical overload induces VEGF in cartilage discs via hypoxia-inducible factor. Am J Pathol. 2004;164:185-92.

25. Pufe T, Kurz B, Petersen W, Varoga D, Mentlein R, Kulow S, et al. The influence of biomechanical parameters on the expression of VEGF and endostatin in the bone and joint system. Ann Anat. 2005;187:461-72.

26. Steinert A, Weber M, Dimmler A, Julius C, Schütze N, Nöth U, et al. Chondrogenic differentiation of mesenchymal progenitor cells encapsulated in ultrahighviscosity alginate. J Orthop Res. 2003;21:1090-7.

27. Reddi $\mathrm{AH}$. Bone morphogenetic proteins: from basic science to clinical applications. J Bone Joint Surg Am. 2001;83A Suppl 1:S1-6.

28. Yuan W, Zhao MD, Yuan FL, Che W, Duan PG, Liu Y, et al. Association of endothelin-1 expression and cartilaginous endplate degeneration in humans. PLoS One. 2013;8:e60062.

29. Saleem M, Qadir MI, Perveen N, Ahmad B, Saleem U, Irshad T, et al. Inhibitors of apoptotic proteins: new targets for anticancer therapy. Chem Biol Drug Des. 2013;82:243-51.

30. Hosseini-Farahabadi S, Geetha-Loganathan P, Fu K, Nimmagadda S, Yang HJ, Richman JM. Dual functions for WNT5A during cartilage development and in disease. Matrix Biol. 2013;32:252-64.

31. Lane Smith R, Trindade MC, Ikenoue $T$, Mohtai M, Das P, Carter DR, et al. Effects of shear stress on articular chondrocyte metabolism. Biorheology. 2000;37:95-107.

32. Smith RL, Carter DR, Schurman DJ. Pressure and shear differentially alter human articular chondrocyte metabolism: a review. Clin Orthop Relat Res. 2004;427(Suppl):S89-95.

33. Zhang Y, Chee A, Shi P, Wang R, Moss I, Chen EY, et al. Allogeneic articular chondrocyte transplantation downregulates interleukin 8 gene expression in the degenerating rabbit intervertebral disk in vivo. Am J Phys Med Rehabil. 2014. Aug 14. [Epub ahead of print].

34. Ryu JH, Yang S, Shin Y, Rhee J, Chun CH, Chun JS. Interleukin-6 plays an essential role in hypoxia-inducible factor $2 a$-induced experimental osteoarthritic cartilage destruction in mice. Arthritis Rheum. 2011;63:2732-43.

35. Civinini R, Nistri L, Martini C, Redl B, Ristori G, Innocenti M. Growth factors in the treatment of early osteoarthritis. Clin Cases Miner Bone Metab. 2013;10:26-9.

36. Krejci P, Krakow D, Mekikian PB, Wilcox WR. Fibroblast growth factors 1, 2, 17, and 19 are the predominant FGF ligands expressed in human fetal growth plate cartilage. Pediatr Res. 2007;61:267-72

37. Blanchard JM. Cyclin A2 transcriptional regulation: modulation of cell cycle control at the G1/S transition by peripheral cues. Biochem Pharmacol. 2000;60:1179-84.

38. Abdollahi T, Robertson NM, Abdollahi A, Litwack G. Inhibition of TRAlL-induced apoptosis by IL-8 is mediated by the p38-MAPK pathway in OVCAR3 cells. Apoptosis. 2005;10:1383-93.

39. Aleshcheva G, Sahana J, Ma X, Hauslage J, Hemmersbach R, Egli M, et al. Changes in morphology, gene expression and protein content in chondrocytes cultured on a random positioning machine. PLoS One. 2013:8:e79057.

40. Duke PJ, Daane EL, Montufar-Solis D. Studies of chondrogenesis in rotating systems. J Cell Biochem. 1993;51:274-82.

41. Chavagnac C, Gai F, Gharib T, Mora C. Astrium spaceplane for scientific missions. Acta Astronaut. 2013:92:172-7.

42. Grosse J, Wehland M, Pietsch J, Ma X, Ulbrich C, Schulz H, et al. Short-term weightlessness produced by parabolic flight maneuvers altered gene expression patterns in human endothelial cells. FASEB J. 2012;26:639-55.

43. Ma X, Pietsch J, Wehland M, Schulz H, Saar K, Hübner N, et al. Differential gene expression profile and altered cytokine secretion of thyroid cancer cells in space. FASEB J. 2014;28:813-35.

44. Ulbrich C, Pietsch J, Grosse J, Wehland M, Schulz H, Saar K, et al. Differential gene regulation under altered gravity conditions in follicular thyroid cancer cells: relationship between the extracellular matrix and the cytoskeleton. Cell Physiol Biochem. 2011;28:185-98.

45. Schmidt W. Quickly changing acceleration forces (QCAFs) vibration analysis on the A300 ZERO-G. Microgravity Sci Technol. 2004;15:42-8.

46. Huang DW, Sherman BT, Lempicki RA. Systematic and integrative analysis of large gene lists using DAVID Bioinformatics Resources. Nat Protoc. 2009;4:44-57.
47. Huang DW, Sherman BT, Lempicki RA. Bioinformatics enrichment tools: paths toward the comprehensive functional analysis of large gene lists. Nucleic Acids Res. 2009;37:1-13

48. Snel B, Lehmann G, Bork P, Huynen MA. STRING: a web-server to retrieve and display the repeatedly occurring neighbourhood of a gene. Nucleic Acids Res. 2000:28:3442-4.

\section{Submit your next manuscript to BioMed Central and take full advantage of:}

- Convenient online submission

- Thorough peer review

- No space constraints or color figure charges

- Immediate publication on acceptance

- Inclusion in PubMed, CAS, Scopus and Google Scholar

- Research which is freely available for redistribution 